\title{
Induced Circular Dichroism of Anionic Porphyrin TPPS Aggregates in DNA Solutions
}

\author{
By Bo LIAO, ${ }^{1,2}$ Benqiao HE, ${ }^{2}$ Ruigang LIU, ${ }^{2}$ and Yong $H_{U A N G}{ }^{2,3, *}$
}

\begin{abstract}
Induced circular dichroism (CD) of achiral anionic tetrakis (4-sulfonatophenyl) porphine (TPPS) in polyanionic DNA solutions was investigated. Induced CD signals of the anionic TPPS aggregates in both cholesteric liquid crystal DNA solutions and isotropic DNA solutions are all observed within an appropriate $\mathrm{pH}$ range. When the $\mathrm{pH}$ value is less than 5, the induced CD signals of TPPS are split in the isotropic DNA solutions, which should result from the helical arrangement of TPPS molecules within the TPPS aggregates with L- or D-type helix. The induced CD signals without splitting of TPPS aggregates in the cholesteric liquid crystal DNA solutions should result from the helical arrangement of the aggregates like molecule screwing along the cholesteric helix axis. When the $\mathrm{pH}$ value is higher than 5.2, no induced CD can be observed in the isotropic solutions and the cholesteric liquid crystal DNA solutions, because the electrostatic repulsion force between the non-protonated TPPS molecules and the bases on DNA chains prevents the chiral induction. The mechanism of the different induced CD signals of TPPS aggregates in the DNA solutions is discussed.
\end{abstract}

KEY WORDS: Porphyrin / DNA / Chirality /

Induced chirality from achiral components is an attractive field in recent years. ${ }^{1-3}$ There are many achiral molecules reported to show chirality induced by certain chiral templates, ${ }^{4-7}$ in which the chirality of achiral molecules can be induced through the interactions of achiral molecules with the chiral templates and the chirality of achiral molecules usually follows the chirality of the templates.

In cholesteric liquid crystals, the local orientation direction of the molecules is perpendicular to the helix axis and is regularly rotated with a constant twist angle. Therefore, the cholesteric liquid crystal structure is believed to be a good chiral template, which can precisely control the molecular orientation through intermolecular interactions. Many achiral dye molecules can be arranged helically in the cholesteric liquid crystals and show induced CD signals, ${ }^{8-14}$ that is liquid crystal induced CD.

DNA is a chiral molecule, which is used as a chiral template to induce many achiral dyes to show induced CD signals. ${ }^{15-21}$ DNA aqueous solution can form cholesteric liquid crystal structure when the concentration is higher than the critical value $^{22}$ and can induce the chirality of achiral dye molecules, such as Ethidium bromide, Bisbenzimide, etc. ${ }^{23}$

Tetrakis(4-sulfonatophenyl) porphine (TPPS) is a achiral dye. It can form stable J-aggregate or $\mathrm{H}$-aggregate, which depends on the $\mathrm{pH}$ value and ionic strength in the system. TPPS aggregates can be easily induced to show chirality by many cationic chiral and achiral templates, such as L- (or D-) Trp film, ${ }^{24}$ gemini-Type Amphiphiles, ${ }^{25}$ polylutamic acid ${ }^{26}$ and polylysine,${ }^{27}$ chitosan, ${ }^{28}$ etc. Usually, these templates are just cationic, which can be directly interacted with the anionic
TPPS. However, there are few reports about induced chirality of TPPS in the DNA solution, because it is believed that polyanion DNA can not directly induce anionic TPPS molecules to show chirality due to the electrostatic repulsion force between DNA and TPPS. Recently, Morii et al. reported the interaction of anionic porphyrins TPPS with DNA in the chain-aligned DNA film, and found that TPPS show weak CD signals in the DNA film. ${ }^{29}$ In this paper, the induced CD signals of both TPPS molecules and the aggregates in cholesteric liquid crystal and isotropic DNA solutions were investigated. The effects of $\mathrm{pH}$ value, the properties of DNA solutions on the induced CD signals were discussed.

\section{EXPERIMENTAL}

Salmon sperm NaDNA ( $6.25 \%$ of $\mathrm{Na}$ ) was purchased from Sigma and used as received. Water-soluble anionic porphyrin TPPS was purchased from Dojindo Laboratories and its molecular structure was given in Figure 1.

The TPPS solutions with $\mathrm{pH}$ range from 1 to 7 were prepared $\left(c_{\text {TPPS }}=0.2 \mathrm{mg} / \mathrm{mL}\right)$. NaDNA was dissolved in the TPPS solutions to form TPPS/DNA cholesteric liquid crystal solutions $\left(c_{\mathrm{DNA}}=160 \mathrm{mg} / \mathrm{mL}\right)$ and isotropic solutions $\left(c_{\mathrm{DNA}}=10 \mathrm{mg} / \mathrm{mL}\right)$. The DNA/TPPS solutions were placed until the DNA was completely dissolved. The DNA/TPPS solution was sandwiched between two pieces of quartz wafers and then sealed with wax (The distance between the two pieces of quartz wafers is about $0.2 \mathrm{~mm}$ ). All samples were equilibrated in dark at least for $7 \mathrm{~d}$ at room temperature before measurements. UV-vis absorption spectra of the DNA/TPPS

\footnotetext{
${ }^{1}$ School of Chemistry and Chemical Engineering, Hunan University of Science and Technology, Xiangtan 411201, China

${ }^{2}$ State Key Laboratory of Polymer Physics and Chemistry, Joint Laboratory of Polymer Science and Materials, Beijing National Lab of Molecular Science, Institute of Chemistry, Chinese Academy of Science, Beijing 100080, China

${ }^{3}$ Laboratory of Cellulose \& Lingnocellulosic Chemistry, Guangzhou Institute of Chemistry, Chinese Academy of Sciences, Guangzhou 510650, China *To whom correspondence should be addressed (Tel: +86-10-68597350, Fax: +86-10-62559373, E-mail: yhuang@cashq.ac.cn).
} 


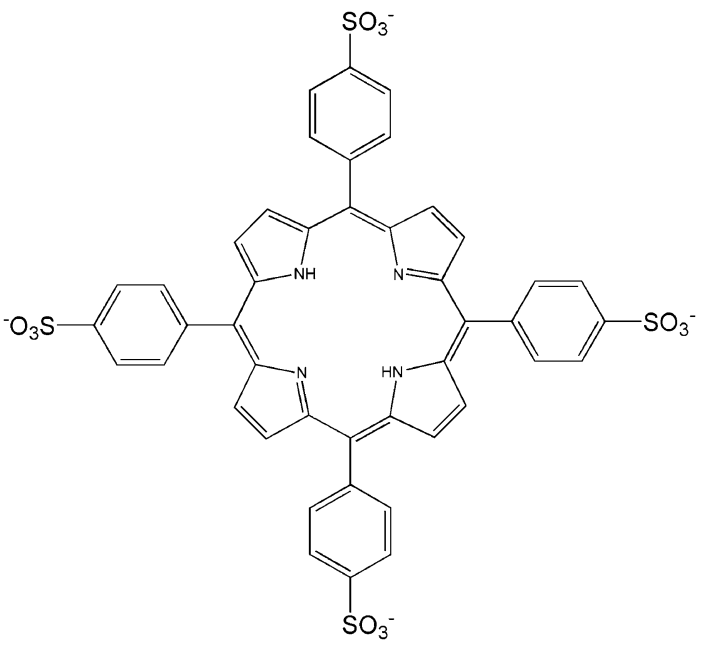

Figure 1. Chemical structure of the non-protonated TPPS molecule.

solutions were recorded by a spectrophotometer (Vrian model UV-530) and circular dichroism (CD) spectra were recorded by a CD spectrophotometer (JASCO, model J-810). In the CD spectrum measurement, the sample was placed perpendicular to the light path to avoid the polarization-dependent reflections and rotated within the film plane to eliminate the possible angle dependence of the $\mathrm{CD}$ signals.

The $\mathrm{pH}$ titration is performed by adding $0.1 \mathrm{M} \mathrm{HCl}$ solution drop by drop to $40 \mathrm{~mL}$ of DNA/TPPS solution $\left(C_{\mathrm{DNA}}=1 \mathrm{mg} /\right.$ $\mathrm{mL}, C_{\text {TPPS }}=0.02 \mathrm{mg} / \mathrm{mL}$ ). The $\mathrm{pH}$ is recorded with the addition of $\mathrm{HCl}$ solution.

\section{RESULTS AND DISCUSSION}

Figure 2a shows the UV-vis absorption spectra of the TPPS/ DNA isotropic solutions with different $\mathrm{pH}$ values and the spectra are varied with $\mathrm{pH}$ value. Three absorption bands at $424 \mathrm{~nm}$ (B-band of H-aggregate), $491 \mathrm{~nm}$ (Soret band of the J-aggregate) and $707 \mathrm{~nm}$ (Q-band of the J-aggregate) are observed when the $\mathrm{pH}$ value is less than 3 . With increasing of the $\mathrm{pH}$ value, the absorption intensity at $491 \mathrm{~nm}$ decreasing, and two new absorption bands at $411 \mathrm{~nm}$ and $434 \mathrm{~nm}$ occur, which are attributed to non-protonated (TPPS ${ }^{4-}$ ) and protonated $\left(\mathrm{H}_{2} \mathrm{TPPS}^{2-}\right)$ TPPS molecules, respectively. The absorption band at $491 \mathrm{~nm}$ disappears when the $\mathrm{pH}$ value is 5 . And only the absorption of the non-protonated TPPS at $411 \mathrm{~nm}$ can be seen when the $\mathrm{pH}$ value is 7 .

Figure $2 b$ shows the CD spectra of the isotropic DNA/TPPS solutions $\left(c_{\text {DNA }}=10 \mathrm{mg} / \mathrm{mL}\right)$ with different $\mathrm{pH}$ values and the $\mathrm{CD}$ spectra are also varied with the $\mathrm{pH}$ value. The $\mathrm{CD}$ signals in the B bands the TPPS $(424 \mathrm{~nm})$ can be observed and these $\mathrm{CD}$ signals are split when the $\mathrm{pH}$ value is not larger than 5 (Spectrum a-e in Figure 2b). However, there is no induced CD signal in the absorption bands of the TPPS when the $\mathrm{pH}$ value of the system is 5.2 or 7 (Spectrum $f$ and $g$ in Figure $2 b$ ), which means that the $\mathrm{CD}$ signals disappear when the $\mathrm{pH}$ value is larger than 5 in the system.
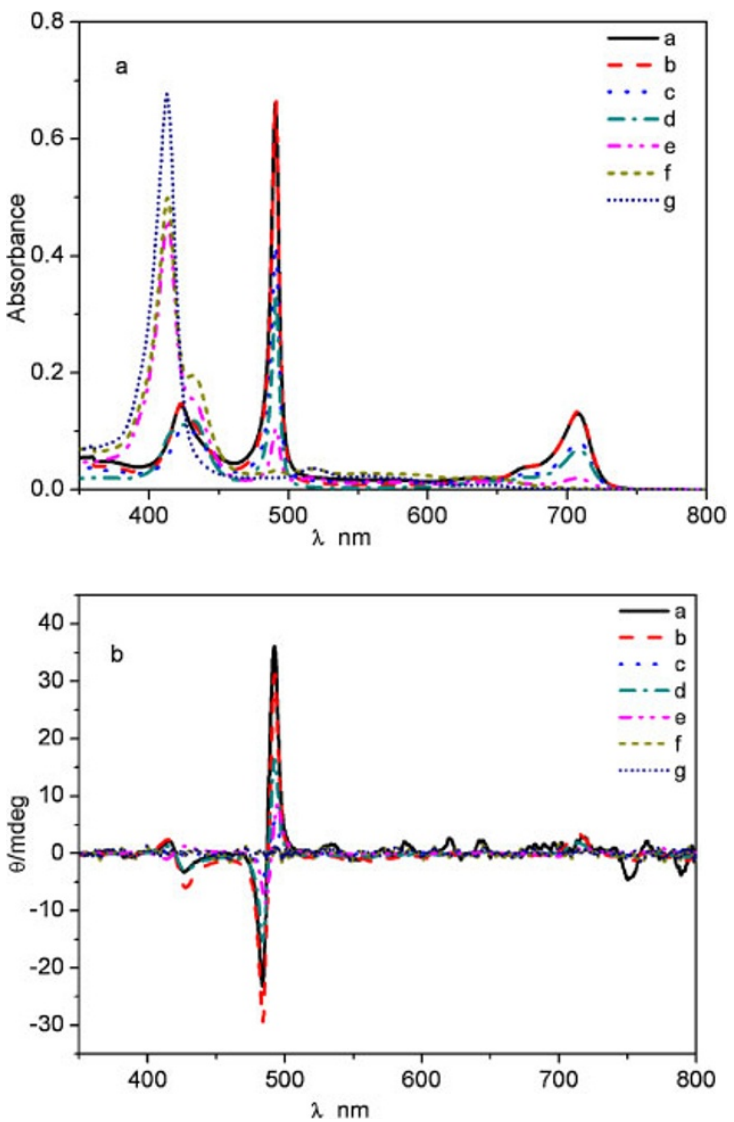

Figure 2. UV-vis absorption (a) and Circular dichroism (b) spectra of the isotropic TPPS/DNA solution with the $\mathrm{pH}$ value of (a) 1.0, (b) 2.0, (c) 3.0, (d) 4.0, (e) 5.0, (f) 5.2 and (g) 7.

It is suggested, from Figure $2 b$, that neither non-protonated nor protonated TPPS single molecules show CD signal in the isotropic DNA/TPPS solution. Only TPPS aggregates show splitting CD signals, which result from $\mathrm{CD}$ couple. The CD signals of TPPS aggregates may come from the two possibilities: one is the helical TPPS aggregates due to self-screwing and the other is the TPPS aggregates without helix but interacting with chiral templates. If the CD signals of TPPS aggregates come from the latter, the protonated TPPS monomers should show induced CD signals in the isotropic TPPS/ DNA solutions, because the protonated TPPS monomers should interact with the bases on DNA chains. However, the protonated TPPS monomer shows no CD signal. Therefore, the splitting CD signals of TPPS aggregates should come from the self-screwing of TPPS aggregates, that is to say, the protonated TPPS monomers are arranged helically within the TPPS aggregates and the TPPS aggregates are formed into L- or Dtype helix just under the driving of the chiral DNA chains.

Figure $3 \mathrm{a}$ is the UV-vis absorption spectra of the TPPS in DNA cholesteric liquid crystal solutions with different $\mathrm{pH}$ values. There are three absorption bands at 424, 491 and $707 \mathrm{~nm}$ when the $\mathrm{pH}$ value of the solution is 1 , it is suggested that the TPPS can also form $\mathrm{J}$ - and $\mathrm{H}$-aggregates in the cholesteric liquid crystal DNA solution. A new absorption band 

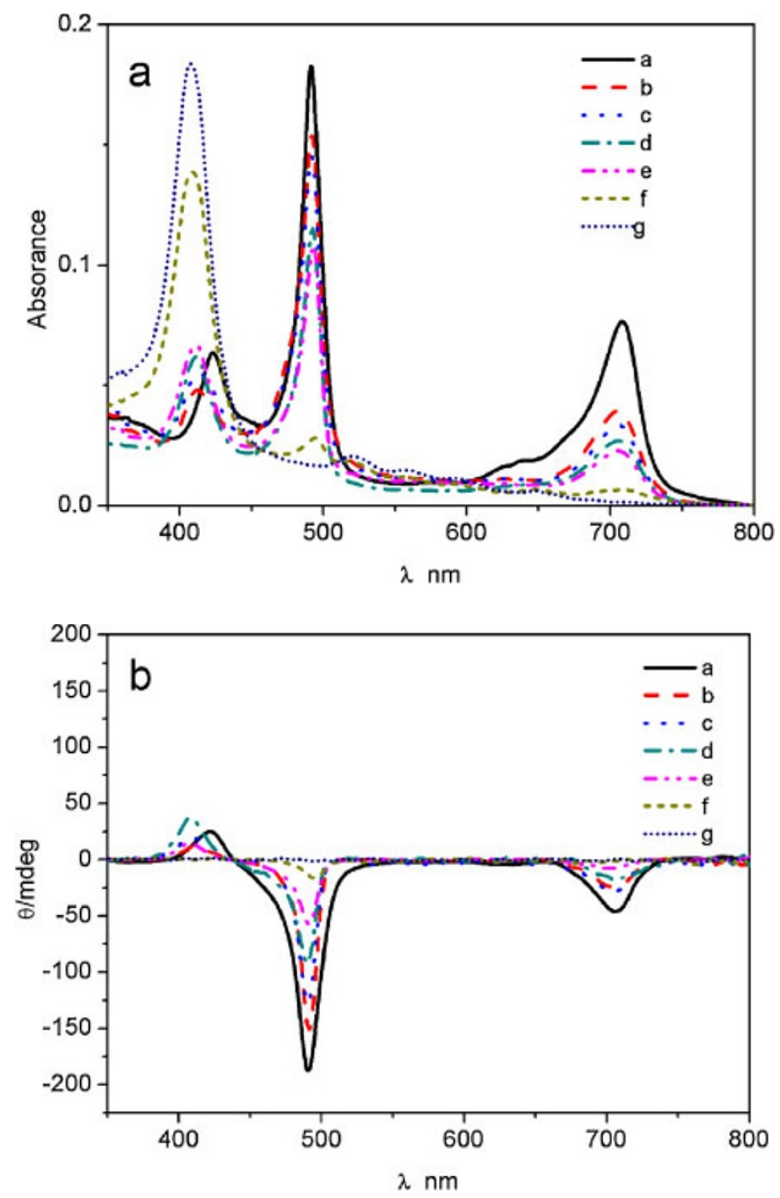

Figure 3. UV-vis absorption (a) and Circular dichroism (b) spectra of the cholesteric liquid crystal TPPS/DNA solution $\left(C_{\mathrm{DNA}}=160 \mathrm{mg} /\right.$ $\mathrm{mL}$ ) with the $\mathrm{pH}$ of (a) 1.0, (b) 2.0, (c) 3.0, (d) 4.0, (e) 5.0, (f) 5.2 and $(\mathrm{g}) 7$.

at $410 \mathrm{~nm}$ appears when the $\mathrm{pH}$ value is in the range from 2 to 5 , which is assigned to the non-protonated TPPS monomers. The absorption band of the non-protonated TPPS monomers becomes very strong, while the absorption band at $491 \mathrm{~nm}$ becomes very weak when the $\mathrm{pH}$ value is 5.2 . The absorption bands of the J-aggregate (at 491 and $707 \mathrm{~nm}$ ) disappear completely and the absorption band of the non-protonated TPPS molecules blue shifts to $408 \mathrm{~nm}$ when the $\mathrm{pH}$ value is 7 , which indicates that there is no TPPS aggregate in the DNA cholesteric liquid crystal solution and only non-protonated TPPS molecules exist in the solution. It is reasonable because TPPS has a low $\mathrm{p} K_{\mathrm{a}}\left(4.9^{30}\right)$ and high $\mathrm{pH}$ does not help protonation of TPPS, or the formation of TPPS aggregates.

Figure $3 \mathrm{~b}$ shows the CD spectra of TPPS in the cholesteric liquid crystal DNA solutions with different $\mathrm{pH}$ values. There are three induced CD signals in the absorption region of TPPS when the $\mathrm{pH}$ value is equal to 1 . The $\mathrm{CD}$ signal at $424 \mathrm{~nm}$ (Bband of $\mathrm{H}$-aggregate) is positive, while the $\mathrm{CD}$ signals at $491 \mathrm{~nm}$ (the Sort band of J-aggregate) and at $707 \mathrm{~nm}$ (the Qband of J-aggregate) are negative. The non-protonated single TPPS molecules also show induced CD signal at $410 \mathrm{~nm}$, besides the induced $\mathrm{CD}$ signals of J-aggregate when the $\mathrm{pH}$ value is smaller than 5 . There is only a weak $C D$ signal at $491 \mathrm{~nm}$ in the Soret band of the TPPS when the $\mathrm{pH}$ value is 5.2, there is no induced CD signal in the absorption region of TPPS when the $\mathrm{pH}$ is 7 .

The results mentioned above reveal that the TPPS aggregates and TPPS molecules are undoubtedly induced to show CD signals in the DNA cholesteric liquid crystal solutions. It is believed that the hydrogen ion $\left(\mathrm{H}^{+}\right)$plays an important role in the induction of the DNA cholesteric liquid crystal structure to the chirality of TPPS monomers and aggregagtes. When the DNA is dissolved in an acidic solution, the bases on the DNA chains are bonded with $\mathrm{H}^{+}$and protonated. At the same time, the TPPS molecules are also protonated in the inner nitrogen when $\mathrm{pH}$ value is low. Therefore, the bases on the DNA chains are attached by the inner protonated nitrogen of the TPPS molecules and the complexation between the anionic TPPS molecules and the DNA chains is formed when the $\mathrm{pH}$ value is low. ${ }^{31}$ It can be concluded that the $\mathrm{H}$-aggregates, J-aggregates and non-protonated molecules of TPPS can be arranged helically along the cholesteric helix axis and show induced CD signals in the DNA cholesteric liquid crystal solution when the $\mathrm{pH}$ value is low due to the interactions between DNA chains and TPPS molecules. But when the $\mathrm{pH}$ value in the solution is increased to be larger than 5.2, the bases on the DNA chains and TPPS molecules are hardly protonated and electrostatic repulsion force exists between the DNA chains and non-protonated single TPPS molecules. Thus, the nonprotonated TPPS molecules are randomly distributed in the DNA cholesteric liquid crystal solution due to the repulsion force between the DNA chains and TPPS molecules and no induced CD of the TPPS molecules can be observed (Spectrum $f$ and $g$ in Figure $3 b$ ). It can be concluded, therefore, that the complexation between liquid crystal molecules and achiral molecules is very important for dyes to show induced CD in the cholesteric environments and this complexation interaction can drive the achiral dyes to be arranged helically along the cholesteric helix axis and finally, the achiral molecules show CD signals in the cholesteric liquid crystal environments. It can be found that the induced CD signal of the H-aggregate of the TPPS is opposite to that of the J-aggregate (Spectrum a in Figure $3 b$ ). This is because the electric transition moment of $\mathrm{H}$-aggregate is perpendicular to that of $\mathrm{J}$-aggregate, ${ }^{32}$ which results in the opposite induced CD signals. ${ }^{8-11}$

From the above results, it can be found that the CD signals of TPPS in the DNA solutions are always related to the $\mathrm{pH}$ value of the solutions. To investigate the relationship between $\mathrm{CD}$ siganls of TPPS and $\mathrm{pH}$ value of solutions, a $\mathrm{pH}$ titration cure of TPPS/DNA solution is shown in Figure 4. As shown in Figure 4, firstly, the $\mathrm{pH}$ value decreases drastically with increasing amount of the adding $\mathrm{HCl}$ solution. Then the $\mathrm{pH}$ value of the solution decreases gently when it is below 5 . Obviously, the results of the $\mathrm{pH}$ titration are consistent with UV-vis and CD results (Figures 2 and 3). It is because the TPPS can not be protonated, when the $\mathrm{pH}$ value is higher than about 5 , the protons existing in the aqueous solution are almost free, thus, the $\mathrm{pH}$ value of the solution can be changed 


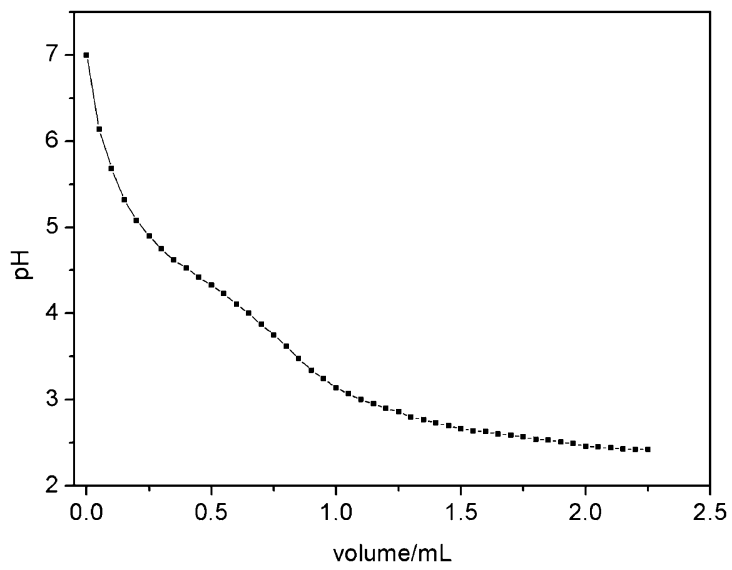

Figure 4. The titration cure of DNA/TPPS solution $\left(C_{\mathrm{DNA}}=1 \mathrm{mg} / \mathrm{mL}\right.$, $C_{\mathrm{TPPS}}=0.02 \mathrm{mg} / \mathrm{mL}$ ).

drastically in the titration progress. As a result, no CD signals of TPPS aggregates can be shown in Figure $2 b$ or Figure $3 b$. However, due to the protonation of TPPS, when the $\mathrm{pH}$ value is below about 5 , parts of protons added can combine with TPPS, consequently, the $\mathrm{pH}$ value of the solution can be decreased gently in the $\mathrm{pH}$ titration progress. It is reasonable that the TPPS self-aggregate and show CD signals of TPPS aggregates.

Comparing the CD signals of the TPPS aggregates in the cholesteric liquid crystal solutions with those in the isotropic solutions, it is interesting that the CD signals of the TPPS aggregates in the DNA cholesteric liquid crystal solutions are not split, while those in the isotropic solution are always split. In the isotropic solutions, neither protonated nor non-protonated TPPS molecules show any CD signals, but the TPPS aggregates show splitting CD signals. This suggests that the splitting CD signals come from the TPPS aggregates itself, that is, they come from the helical arrangement of the TPPS molecules within the aggregate, just as illustrated in Figure 5a, the TPPS aggregates are formed into helix under the driving of DNA. In the DNA cholesteric liquid crystal solutions, the CD signals without splitting at the absorption bands of the TPPS aggregate can be observed. It is proposed that the aggregates itself are achiral in the DNA liquid crystal solutions and the CD signals just come from the liquid crystal induced circular dichroism. The difference of the chiralities of TPPS aggregates in the isotropic and liquid crystal solutions may result from the different physical sizes of the aggregates in the two kinds of solutions. The adsorption spectral width of the TPPS aggregate is narrower than that of the TPPS molecules by a factor of $\sqrt{ } \mathrm{N},{ }^{33,34}$ where $\mathrm{N}$ represents the spectroscopic aggregation number. The full width at half-height values of the Soret band $(491 \mathrm{~nm})$ of the $J$ aggregate in the isotropic and liquid crystal solutions is about 334 and $666 \mathrm{~cm}^{-1}$, respectively, which suggests that the spectroscopic aggregation number in the isotropic solutions is fourfold that of the liquid crystal solutions. In the case of the isotropic solutions, TPPS aggregates can grow freely into those with larger size, and with self-screwing morphology. However, in the cholesteric liquid crystal solutions, the growth of the aggregate is confined between cholesteric layers and at the same time, the selfscrewing of the TPPS aggregates may be forbidden. Such different aggregation behavior may affect the chiralities of the TPPS aggregates in the DNA solutions. However, due to the induction of the DNA cholesteric liquid crystal structure, the aggregates can be oriented like single molecules in the cholesteric structure. As illustrated in Figure 5b, the TPPS aggregates are located between two cholesteric layers, and the

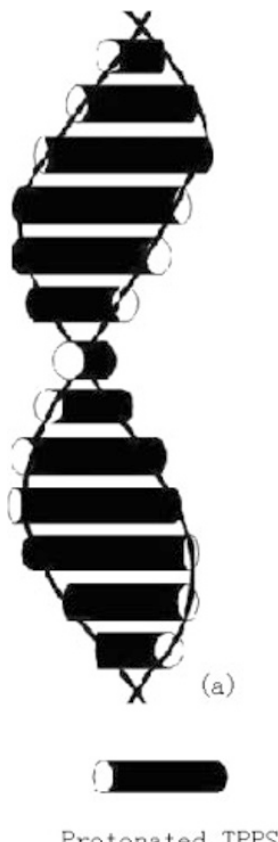

Protonated TPPS

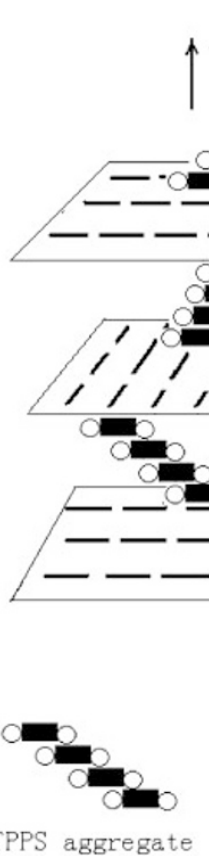

TPPS aggregate

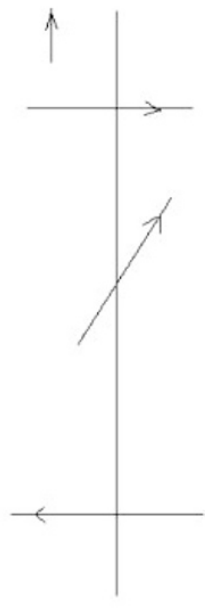

(b)
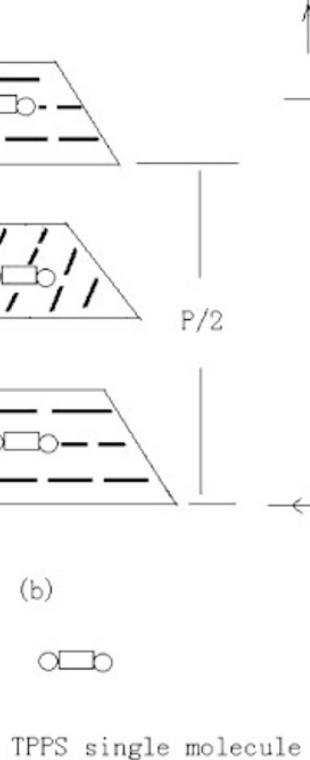

Figure 5. Illustration of induced circular dichroism origin of TPPS in DNA solutions: (a) in isotropic, (b) in cholesteric liquid crystal. 
chains of the TPPS aggregates are paralleled to the chains of DNA in the cholesteric layer. The TPPS aggregates just like single molecules screw along the cholesteric helix, along the cholesteric helix axis to look, which just like the cholesteric structure. Therefore, the TPPS aggregates show CD signals. However, the TPPS aggregates in the successive layers can not be interacted with each other because the distance between them is too lager to couple each other. Therefore, the TPPS aggregates in cholesteric liquid crystal DNA solutions show the $\mathrm{CD}$ signals without splitting. When the $\mathrm{pH}$ value is not larger than 5, the non-protonated TPPS monomers can be also oriented by the chains of DNA due to the interaction of nonprotonated TPPS and protonated bases of DNA, and be arranged along the cholesteric helix, as illustrated in Figure 5b, so the non-protonated single TPPS molecules also show CD signal.

\section{CONCLUSIONS}

Induced CD signals of the anionic TPPS aggregates in both cholesteric liquid crystal DNA solutions and isotropic DNA solutions are all observed by adjusting the $\mathrm{pH}$ value., The induced CD signals are split in the isotropic DNA solutions, when the $\mathrm{pH}$ value is less than 5 , which may result from the helical arrangement of TPPS molecules within the TPPS aggregates with L- or D-type helix. The induced CD signals of TPPS aggregates are not split in the cholesteric liquid crystal DNA solutions, which should result from the helical arrangement of the aggregates like molecule screwing along the cholesteric helix axis. In the cholesteric liquid crystal DNA solution, $\mathrm{H}$ - and J-aggregates of TPPS are arranged in lefthanded helix, which follows the cholesteric liquid crystal structure. When the $\mathrm{pH}$ value is higher than 5, no induced CD can be observed in the isotropic solutions and the cholesteric liquid crystal DNA solutions, because the electrostatic repulsion force between the non-protonated TPPS molecules and the bases on DNA chains prevents the chiral induction.

Received: April 20, 2009

Accepted: May 26, 2009

Published: July 9, 2009

\section{REFERENCES}

1. T. Kawasaki, M. Tokuhiro, N. Kimizuka, and T. Kunitake, J. Am. Chem. Soc., 123, 6792 (2001).

2. H. Gao, Y. Isobo, K. Onimura, and T. Oishi, Polym. J., 39, 764 (2007).
3. T. Takata, F. Ishiwari, T. Sato, R. Seto, and Y. Koyama, Polym. J., 40, 846 (2008)

4. H. Von Berlepsch, C. Bottcher, A. Ouart, C. Burger, S. Dähne, and S. Kirstein, J. Phys. Chem. B, 104, 5255 (2000).

5. H. von Berlepsch, C. Böttcher, A. Ouart, M. Regenbrecht, S. Akari, U. Keiderling, H. Schnablegger, S. Dähne, and S. Kirstein, Langmuir, 16, 5908 (2000).

6. S. Kirstein, H. V. Berlepsch, C. Böttcher, C. Burger, A. Ouart, G. Reck, and S. Dähne, ChemPhysChem, 1, 146 (2000).

7. U. De Rossi, S. Dähne, S. C. J. Meskers, and H. P. J. M. Dekkers, Angew. Chem., Int. Ed., 35, 760 (1996).

8. F. D. Saeva and G. R. Olin, J. Am. Chem. Soc., 95, 7882 (1973).

9. F. D. Saeva, P. E. Sharpe, and G. R. Olin, J. Am. Chem. Soc., 95, 7656 (1973).

10. F. D. Saeva, J. Am. Chem. Soc., 94, 5135 (1972).

11. F. D. Saeva, P. E. Sharpe, and G. R. Olin, J. Am. Chem. Soc., 95, 7660 (1973).

12. M. Sisido, H. Narisawa, R. Kishi, and J. Watanabe, Macromolecules, 26, 1424 (1993).

13. F. D. Saeva and J. J. Wysocki, J. Am. Chem. Soc., 93, 5928 (1971).

14. X. M. Dong and D. G. Gray, Langmuir, 13, 3029 (1997).

15. R. A. Garoff, E. A. Litzinger, R. E. Connor, I. Fishman, and B. A. Armitage, Langmuir, 18, 6330 (2002).

16. X. Chen, L. Li, and M. Liu, Langmuir, 18, 4449 (2002).

17. M. Wang, I. Dilek, and B. A. Armitage, Langmuir, 19, 6449 (2003).

18. C. Bombelli, S. Borocci, M. Diociaiuti, F. Faggioli, L. Galantini, P. Luciani, G. Mancini, and M. G. Sacco, Langmuir, 21, 10271 (2005).

19. J. L. Seifert, R. E. Connor, S. A. Kushon, M. Wang, and B. A. Armitage, J. Am. Chem. Soc., 121, 2987 (1999).

20. A. Chowdhury, S. Wachsmann-Hogiu, P. R. Bangal, I. Raheem, and L. A. Peteanu, J. Phys. Chem. B, 105, 12196 (2001).

21. M. Wang, G. L. Silva, and B. A. Armitage, J. Am. Chem. Soc., 122, 9977 (2000).

22. B. Liao, B. Q. He, S. X. Chen, and Y. Huang, Polym. J., 38, 597 (2006).

23. F. Livolant and M. F. Maestre, Biochemistry, 27, 3056 (1988).

24. X. D. Zhai, L. Zhang, and M. H. Liu, J. Phys. Chem. B, 108, 7180 (2004).

25. L. Zhang, J. Yuan, and M. H. Liu, J. Phys. Chem. B, 107, 12768 (2003).

26. S. Geremia, L. Di Costanzo, G. Nardin, L. Randaccio, R. Purrello, D. Sciotto, R. Lauceri, and F. Pichierri, Inorg. Chem., 43, 7579 (2004).

27. R. Purrello, L. Monsu Scolaro, E. Bellacchio, S. Gurrieri, and A. Romeo, Inorg. Chem., 37, 3647 (1998).

28. B. Liao, R. G. Liu, and Y. Huang, Polym. J., 39, 1071 (2007).

29. N. Morii, G. Kido, T. Konakahara, and H. Morii, Biomacromolecules, 6, 3259 (2005).

30. N. C. Maiti, M. Ravikanth, S. Mazumadar, and N. Periasamy, J. Phys. Chem., 99, 17192 (1995).

31. R. Lauceri, R. Purrello, S. J. Shetty, and M. G. H. Vicente, J. Am. Chem. Soc., 123, 5835 (2001).

32. M. Y. Choi, J. A. Pollard, M. A. Webb, and J. L. McHale, J. Am. Chem. Soc., 125, 810 (2003).

33. E. W. Knapp, Chem. Phys., 85, 73 (1984).

34. E. W. Knapp, P. O. J. Scherer, and S. F. Fisher, Chem. Phys. Lett., 111, 481 (1984). 